niversity of Thi_Qar Journal for Engineering Sciences http://www.doi.org/10.31663/tqujes.10.2.368(2019)

Vol 10.2 (September 2019)
ISSN:2664-5572( online)

ISSN:2664-5564 (print)

Available at http://jeng.utq.edu.iq

utjeng@utq.edu.iq

\title{
Experimental Deformation Analysis of Ship Hull Subjected to Vibration Waves
}

\author{
Kadim Karim Mohsen ${ }^{\dagger}$, Nisreen N. Dawod ${ }^{\star}$ \\ ${ }^{\dagger}$ Mechanical Engineering Department, College of Engineering, Thi-Qar University, Iraq \\ ${ }_{*}$ Mechanical Engineering Department, College of Engineering, Thi-Qar University, Iraq
}

\begin{abstract}
This paper includes an experimental study of the effect of dynamical vibration (harmonic waves) or wind on the deformation of the ship hull when it is in the case of pitching motion and rolling. The aim of this paper is to calculate the strains of the ship as a result of the effect of waves on it. Aluminum alloy was used to build the frame of the model with suitable dimensions, and then fixed the model on the vibrating system which consists of number of springs with limiting stiffness. Vibrating system supported with means to generate waves with $(0.75 \mathrm{~Hz}, 1 \mathrm{~Hz}, 1.25 \mathrm{~Hz})$ frequencies. The deformations are measured at the pitching and rolling motion of the model. The results showed that the strains of the model in the pitching motion greater than the rolling motion. When the frequency increases, the strains are increases.
\end{abstract}

Keywords: Dynamical strain, Signals, vibration response, Hogging \&Sagging.

\section{Introduction}

With the evolution of the background of the times, ships are becoming larger and high power, the rigidity of the shafting system also been increased[1,2], but the rigidity of the hull is relatively smaller, so the effects of hull deformation of ship for the shafting system cannot be ignored, each bearing position will be changed because of the hull deformation, resulting in ship shafting work changed, endanger the safety of ship navigation specially the kind ships of thick short tail shaft, such as large bulk carriers and tankers, the rigidity of ship shafting is relatively large, the deformation of the hull be sensitive.

Therefore, the study of ship deformation under wave loads is very important $[3,4]$. When the ship meets the two waves that lead to the Sagging of the hull that these waves cause longitudinal stresses along the hull of the ship. These stresses are called hogging and sagging stresses and affect these stresses on all hull panels of the ship, both top surface panels or lower bottom panels as well as affect the longitudinal and transverse stresses as well as extenders. Primary loading is caused by global ship bending loads. [5]. There are six motions of the ships can be classified into:A-Translational motion

It's divided to three movements:-

1-Force linear motion forward (surging): It arises from the movement of the ship forward.

2- Force linear motion vertical (Heaving): it is arises from the impact of the movement of the waves of the sea on the ship, which is lift it then download them in vertical movement linear.

3-Force linear motion side (swaying): it arises from the impact of the movement of the waves of the sea on the ship, which is driven by a linear side motion.

b- Rotational motion

It's divided to three movements:
1-A rotational force around the longitudinal axis (Rolling): it is a regular rolling resulting from the tilt of the ship on either side around the longitudinal axis of the ship.

2-The rotational force around the axial axis (pitching): it is the rolling force due to the tilt of the ship forward and backward around the axial axis.

3-A rotational force around the vertical axis (yawing): it is a force motion of the ship to the right and to the left or around the vertical axis.

These six forces affect the hull of the ship while moving in addition to three forces static ship weight, buoyancy and water pressure [11].

Figure .1 shown the six types of ship motions

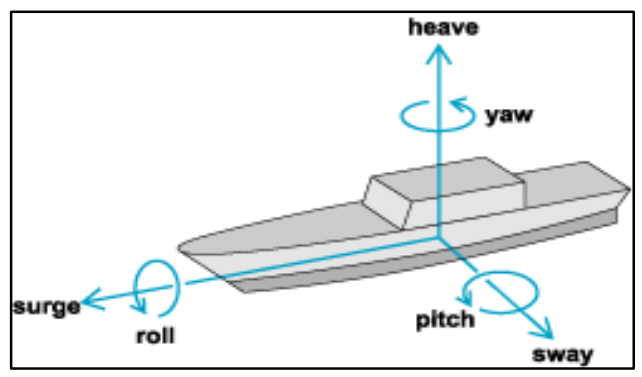

Fig.1 ship motions [12]

Many efforts have been spent to analyze the deformation of ship hull under the effect of vibration that induced by sea waves (forced vibration).The main purpose of this paper is to study the dynamic behavior of a ship hull under the influence of regular waves. Studying the deformations of ship hull structure with varying frequency of the wavesin state pitching and rolling motion of the ship. 


\section{Literature view}

Ingo Drummen et al[6], advanced experimentally and numerically investigation of fatigue stresses due to waveinduced vibrations in a container ship in head seas. It is known that cracks of fatigue occur in ships welded to a number of decades. For the large oceans, the induced wave oscillations can depend on the trade and cause up to $50 \%$ of the fatigue damage. The outcomes showed that the vibration induced by the router contributed about $40 \%$ of the total damage to fatigue. A numerical pathway was predicted to replicate the vector damage well but was found to exaggerate the total damage to fatigue by $50 \%$.Apostolos

Papanikolaou [7], studied holistic design and optimization of ships. Design of ship is a complex endeavor that requires the successful coordination of many disciplines, both natural and technical, non-technical experts and expert design solutions. The results showed that the approach to mathematical examples of multi - purpose tools is very important, which greatly enhances the quality of the ship 's design even if it is applied to vessels that have already been improved by traditional methods. R.A. Ibrahim. and I.M. Grace [8], advanced modeling of ship roiling dynamics and its coupling with heaving and pitching. The purpose of this study is to provide equations for nonlinear motion in roll, heave and pitch based on physical grounds. The study includes an assessment of random and roll stochastic stability utilized to estimate the capsizing probability and parameter identification. Wang Yanwen1 and et al [9] submitted the study on the effect of wave load on the ship hull deformation. The paper uses ANSYS element software dividing mesh of the whole ship, and then the APDL is used to calculate the dynamic pressure of wave. The results show that under the same conditions the hull with different deformation to the different phase of the waves, hull deformation showed a sinusoidal curve along with the movement of wave phase, with respect to $4 \mathrm{~m}$ wave height, the shafting is obviously raised under $6 \mathrm{~m}$ wave heights, but with smaller fluctuations in movement wave Li Yan and et al [10] studied the influence of wave load on the vibration of shaft system. Using the AQWA software to calculate the wave hydrodynamic pressure and using the APDL language to compile the program loading implement wave loads on hull automatically different wave high, researching the changes of separate support stiffness and all the support stiffness for shafting natural frequency. The results show that: from the point of separate bearing stiffness changes view, the stern tube bearing stiffness has effect on the low order natural frequency of the shaft is relatively large, no effect on the high order frequency almost; with the increase of wave height, bearing oil film rigidity improved, the shafting vibration frequency decreases. Therefore, in Consideration of hull deformation, this paper lays a foundation for the research on the vibration of the shafting.

\section{Model Description}

The model that was utilized in this work was the ship hull which was manufactured from aluminum material .Frame, $\mathrm{T}$-section, machined in milling machines and assembly by welding machines. The Actual dimensions of the ship showed in table 1.All real dimensions are scaled by (1:170).
Table (1). Actual and scale dimensions of the ship hull.

\begin{tabular}{|c|c|c|}
\hline $\begin{array}{c}\text { Dimension of the ship } \\
\text { hull }\end{array}$ & Actual & $\begin{array}{c}\text { To } \\
\text { scale }\end{array}$ \\
\hline $\begin{array}{c}\text { Length Over All (O.A.) } \\
(\mathrm{m})\end{array}$ & $189.94 \mathrm{~m}$ & 0.56 \\
\hline $\begin{array}{c}\text { Length Between } \\
\text { Perpendicular (B.P.) (m) }\end{array}$ & $182.00 \mathrm{~m}$ & 1 \\
\hline $\begin{array}{c}\text { Molded Breadth (MLB.) } \\
(\mathrm{m})\end{array}$ & $32.26 \mathrm{~m}$ & 0.189 \\
\hline $\begin{array}{c}\text { Molded Depth (MLD.) } \\
\text { Extreme Draught (E.H.) } \\
(\mathrm{m})\end{array}$ & $17.30 \mathrm{~m}$ & 0.10 \\
\hline $\begin{array}{c}\text { Deadweight (M.T) } \\
\end{array}$ & 53,553 & 0.072 \\
\hline
\end{tabular}

The parts are machined and assembly to form the model as shown in figure (2).

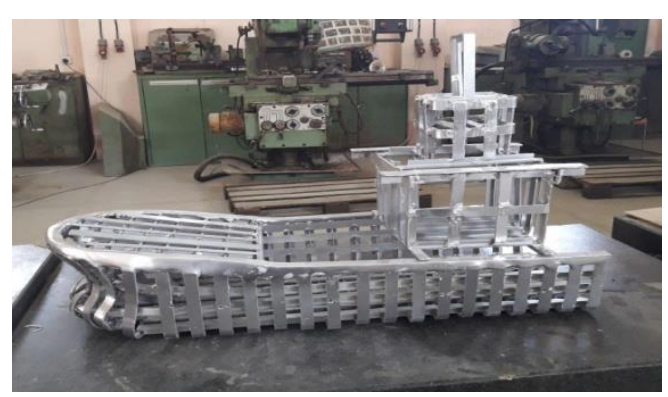

Fig(2) Final form of ship hull model.

\section{Experimental set up}

The testing of strains achieved by installed sensors train gage in middle of ship hull model as shown in figure (4). When the exciter was running to generate the longitudinal motion on the hull, the strain was measured by that sensors and the signal was extracted by utilized program of signal express. The process was repeated for each case with a change in the number of springs $(4 \mathrm{~s}, 8 \mathrm{~s}, 10 \mathrm{~s})$ as shown in figure (5), and with frequency change three times in each case $(0.75 \mathrm{~Hz}, 1 \mathrm{~Hz}, 1.25 \mathrm{~Hz})$. The rolling movement can be produced by the same method. The spring characteristics shown in table (2). The stiffness of the spring calculated by using Quasar tensile test device and Graph Work program. As shown in figure (3). 


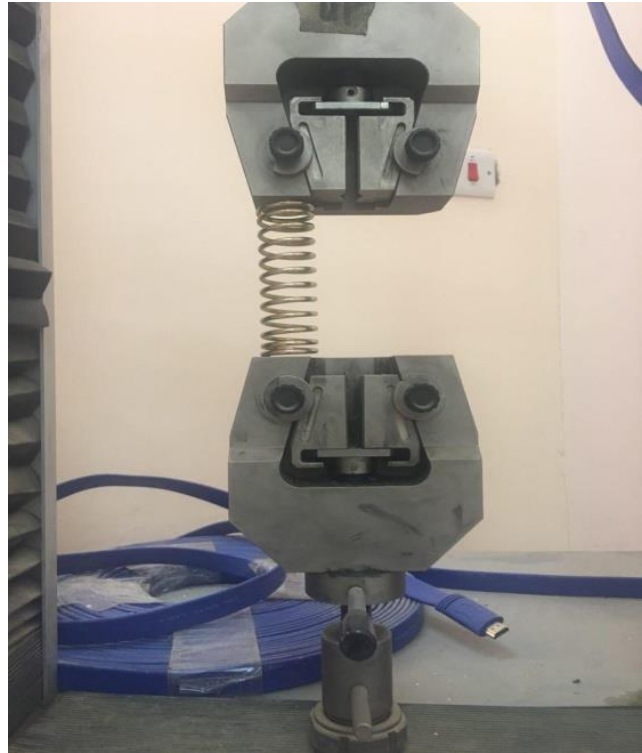

Fig(3) spring stiffness calculation by using tensile testing device.

Table (2) characteristics of spring.

\begin{tabular}{|l|l|l|l|l|l|}
\hline $\begin{array}{l}\mathrm{d} \\
(\mathrm{mm})\end{array}$ & $\begin{array}{l}\mathrm{D}_{\mathrm{i}} \\
(\mathrm{mm})\end{array}$ & $\begin{array}{l}\mathrm{D}_{\mathrm{o}} \\
(\mathrm{mm})\end{array}$ & $\mathrm{n}$ & material & $\begin{array}{l}\mathrm{K} \\
(\mathrm{N} / \mathrm{mm})\end{array}$ \\
\hline 3 & 24 & 30 & 12 & steel & 2.3 \\
\hline
\end{tabular}

Where , $\mathrm{d}$ : wire spring diameter , $\left(\mathrm{D}_{\mathrm{i}}, \mathrm{D}_{0}\right)$ internal and external of spring diameter, $\mathrm{n}$ : number of total turns , $\mathrm{K}$ : stiffness of spring $(\mathrm{N} / \mathrm{mm})$.

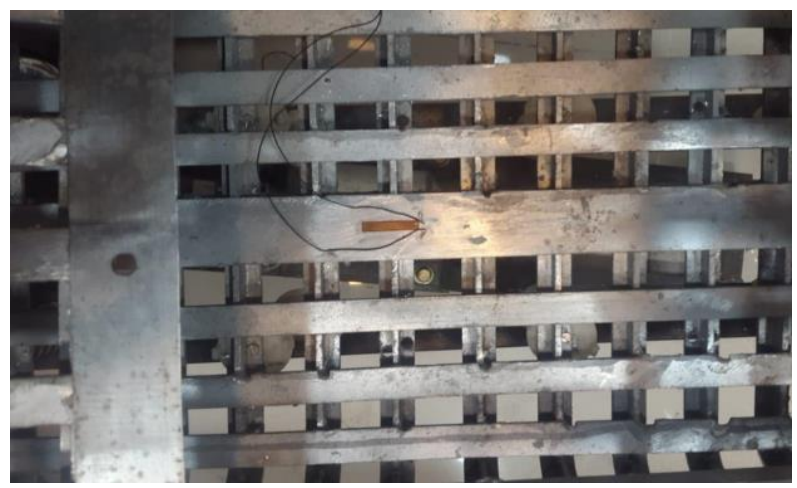

Fig (4) Installing sensor in the middle of ship hull.

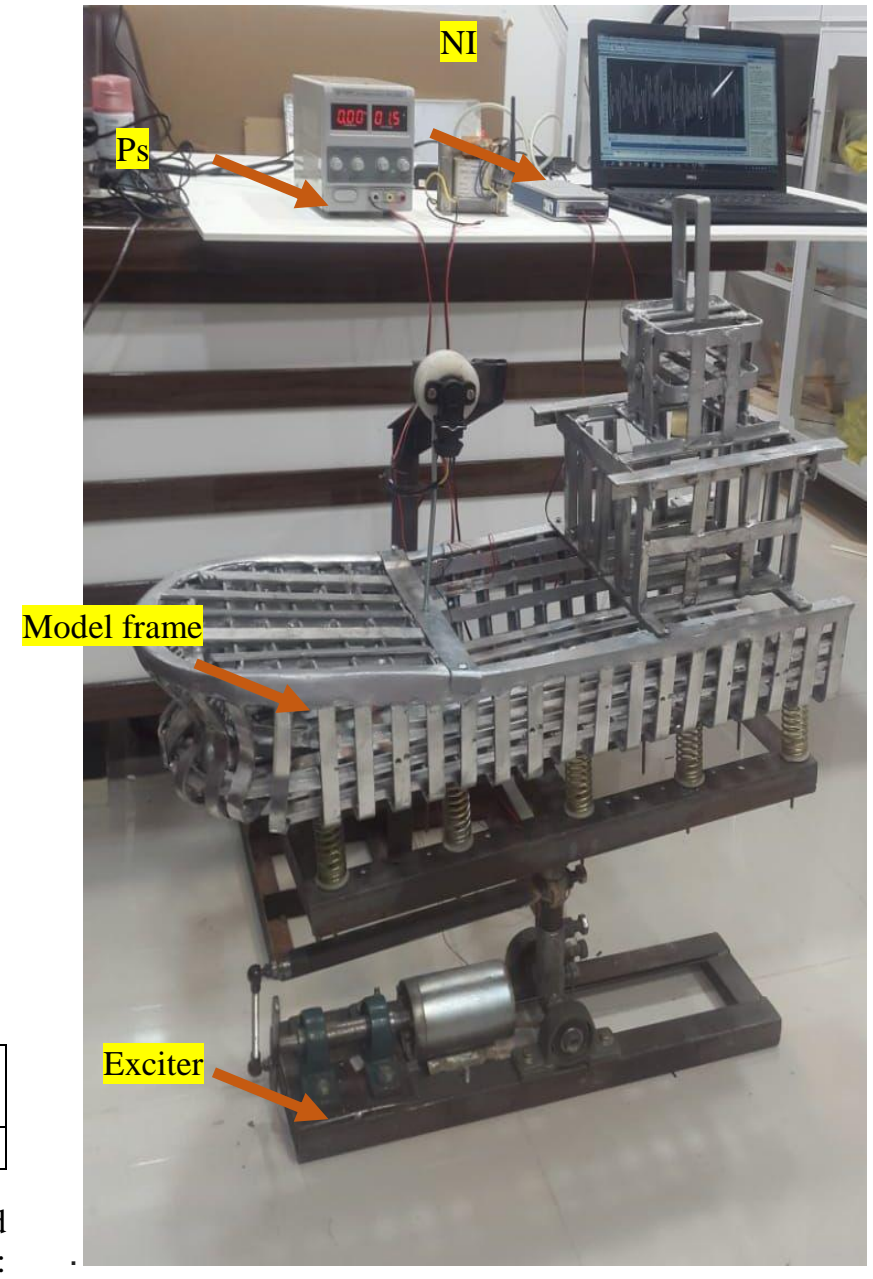

Fig (5)Bench top testing with installing the spring in model of ship hull.

\section{Results and Discussions}

5.1Strain of amidships point in pitching movement (MP) The variation of dynamical vibration strain with the time at external frequency $(0.75 \mathrm{~Hz})$ and four springs $(4 \mathrm{~s})$ is shown in figure (6). It can be illustrated that the variation in dynamical strain oscillating is irregular between hogging and sagging from rest until to time $(6 \mathrm{sec})$. The frequency of the strain wave is much greater than the frequency of the external router and the highest value of the strain reaches to $(130 \mu)$.

Figure (7) shows the variation of dynamical vibration strain with the time at external frequency $(1 \mathrm{~Hz})$ and four springs $(4 \mathrm{~s})$. It can be noted in this process that the dynamical vibration strain was non uniform this process oscillated between tension and compression strain from rest to $(6 \mathrm{sec})$.The frequency of the strain wave is much greater than the frequency of the external router and the highest value of the strain reaches to $(120 \mu)$.

Figure (8) from this figure it can be noted the variation of dynamical vibration strain with the time at external frequency $(1.25 \mathrm{~Hz})$ and four $\operatorname{spring}(4 \mathrm{~s})$. 'Noted that the maximum value of strain $(150 \mu)$ hogging and ($150 \mu$ )sagging.

The variation of dynamical vibration strain with the time at external frequency $(0.75 \mathrm{~Hz})$ and eight springs $(8 \mathrm{~s})$ is shown 
in figure (9). From this figure it can be seen that the dynamical strain behavior of response by the strain variation oscillating between hogging and sagging from rest until to time $(6 \mathrm{sec})$. The frequency of the strain wave is much greater than the frequency of the external router and the highest value of the strain reaches to $(80 \mu)$.

Figure (10) illustrates the variation of dynamical vibration strain with the time at external frequency $(1 \mathrm{~Hz})$ and eight springs $(8 \mathrm{~s})$. It can be observed that the variation in dynamical strain oscillating is irregular between hogging and sagging from rest until to time $(6 \mathrm{sec})$.The frequency of the strain wave is much greater than the frequency of the external router and the highest value of the strain reaches to $(110 \mu)$.

Figure (11) presents the variation of dynamical vibration strain with the time at external frequency $(1.25 \mathrm{~Hz})$ and eight springs (8s). It can shown that

The variation in dynamical strain oscillating is irregular between hogging and sagging from rest until to time $(6 \mathrm{sec})$.The frequency of the strain wave is much greater than the frequency of the external router and the highest value of the strain reaches to $(140 \mu)$.

Figure (12) presents the variation of dynamical vibration strain with the time at external frequency $(0.75 \mathrm{~Hz})$ and ten springs (10s). It can be shown that the dynamical strain response variation between the hogging and sagging from rest to time $(6 \mathrm{sec})$.the value of strain reach to $(75 \mu)$ at time $(5.5 \mathrm{sec})$ and $(-75 \mu)$ at time $(5.6 \mathrm{sec})$.

Figure (13) illustrates the variation of dynamical vibration strain with the time at external frequency $(1 \mathrm{~Hz})$ and ten springs (10s). It can be seen that the dynamical strain response variation between the tension and compression from rest to time $(6 \mathrm{sec})$.the value of strain reach to $(100 \mu)$ and $(-100 \mu)$.

Figure (14) shows the variation of dynamical vibration strain with the time at frequency of wave $(1.25 \mathrm{~Hz})$ and ten spring (10s).It can be observed that the dynamical strain response variation between the hogging and sagging from rest to time $(6 \mathrm{sec})$.the value of strain reach to $(140 \mu)$ and $(-140 \mu)$. These results are consisted with other studies in the same work area.

of references $[9,10]$.

Strain

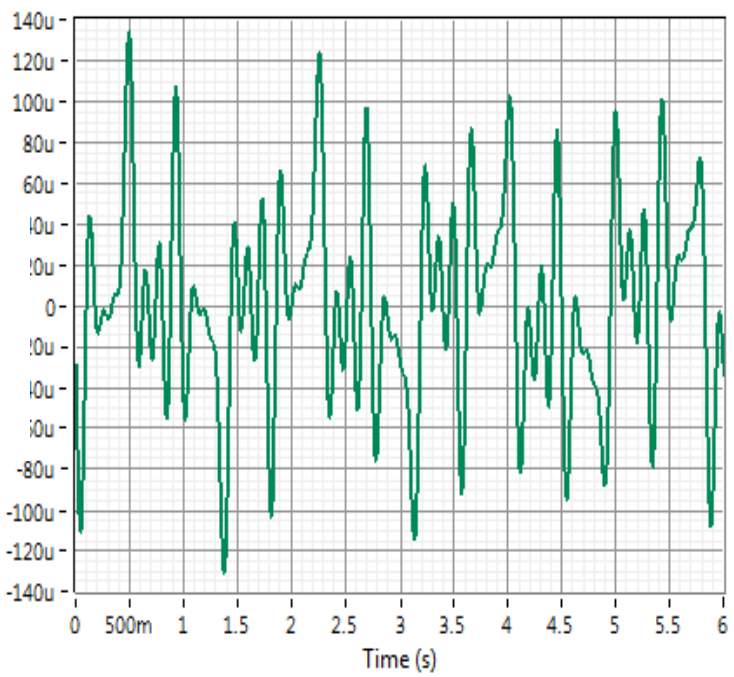

Strain

Fig(6) strain verses time for four spring and $0.75 \mathrm{~Hz}$

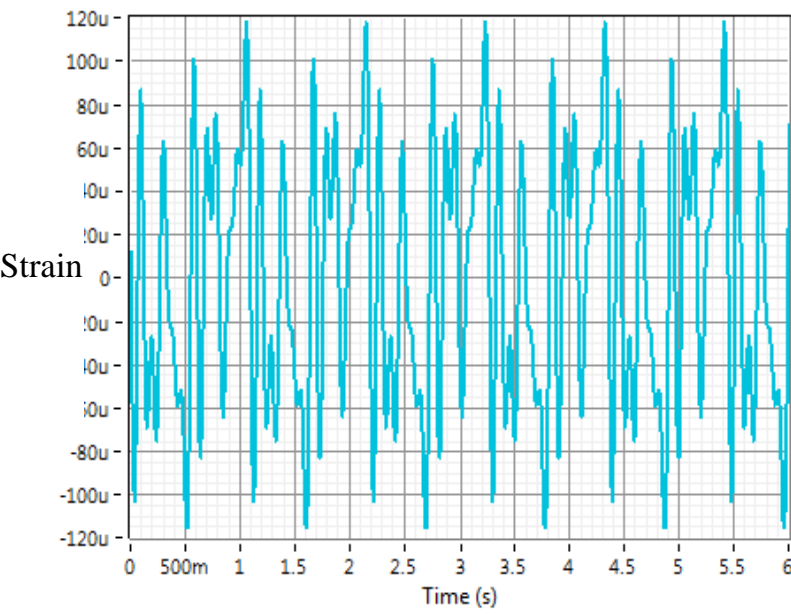

Fig (7) Strain verses time for four spring and $1 \mathrm{~Hz}$

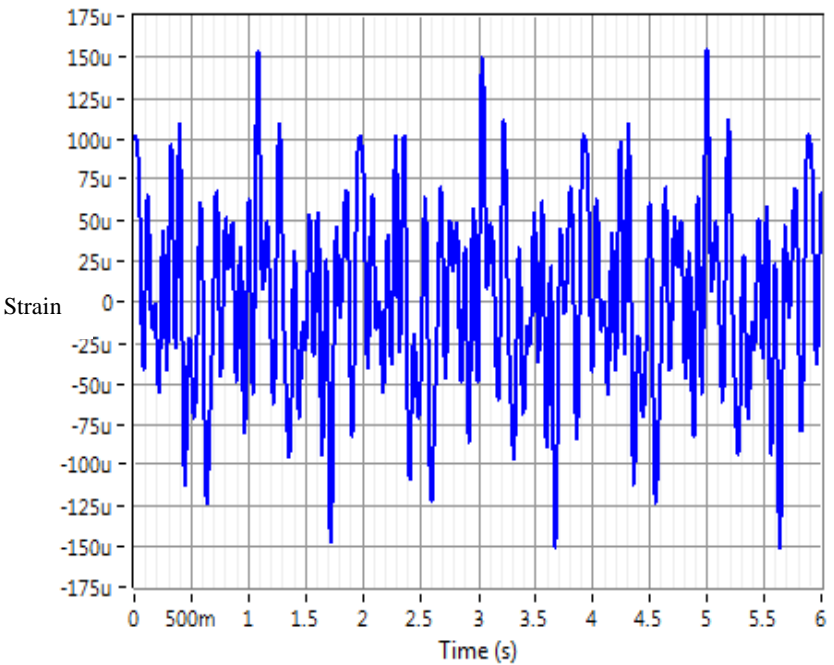

Fig (8) Strain verses time for four spring and $1.25 \mathrm{~Hz}$

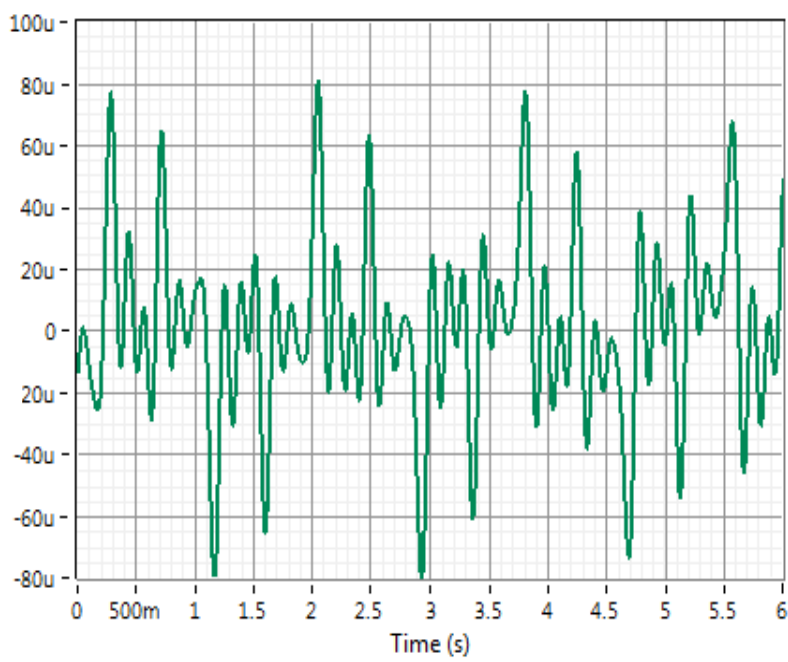

Fig (9) Strain verses time for eight spring and $0.75 \mathrm{~Hz}$ 


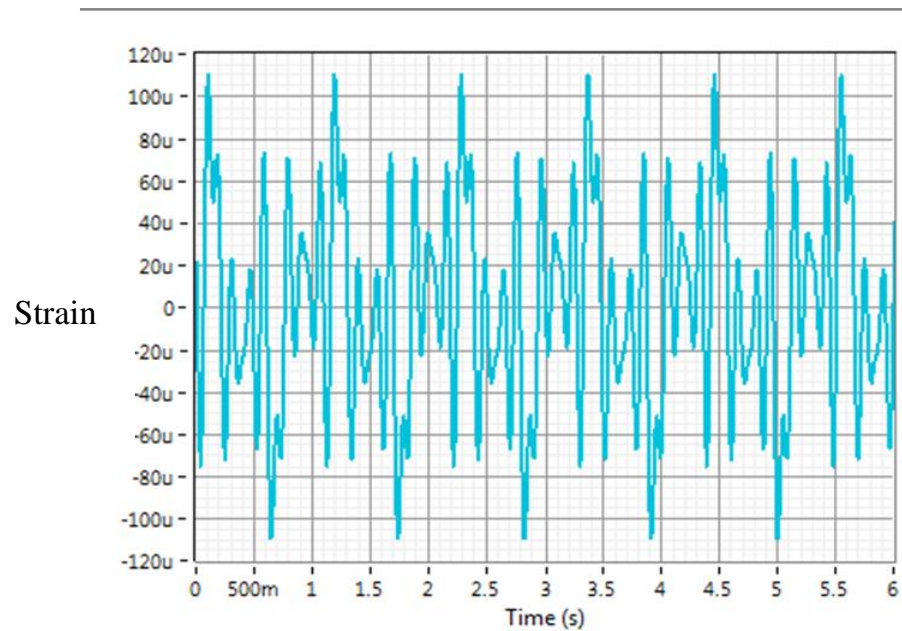

Fig (10) Strain verses time for eight spring and $1 \mathrm{~Hz}$

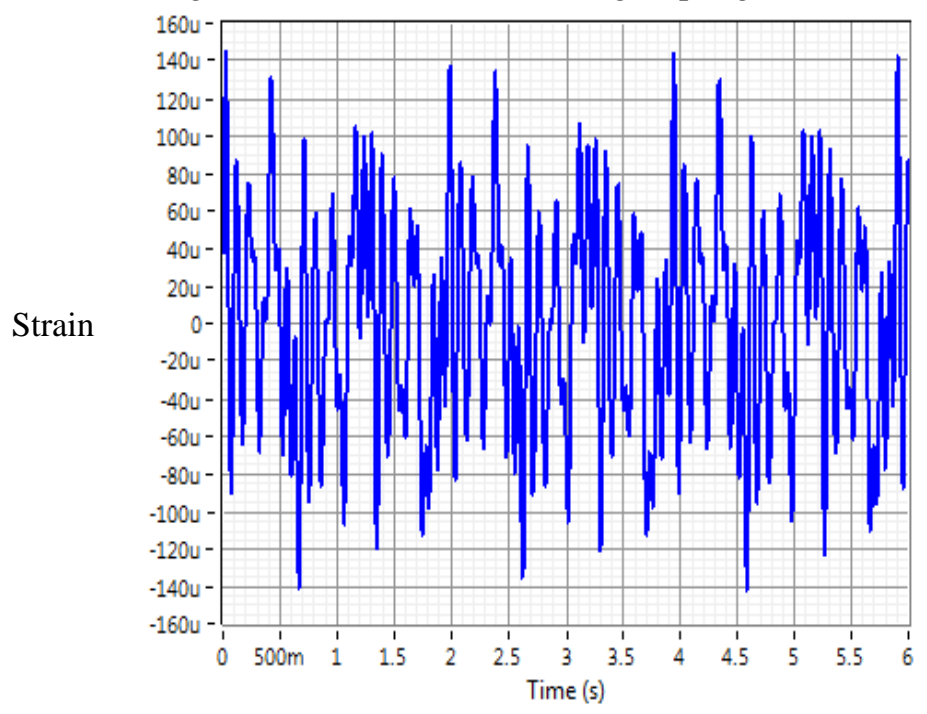

Fig (11) Strain verses time for eight spring and $1.25 \mathrm{~Hz}$

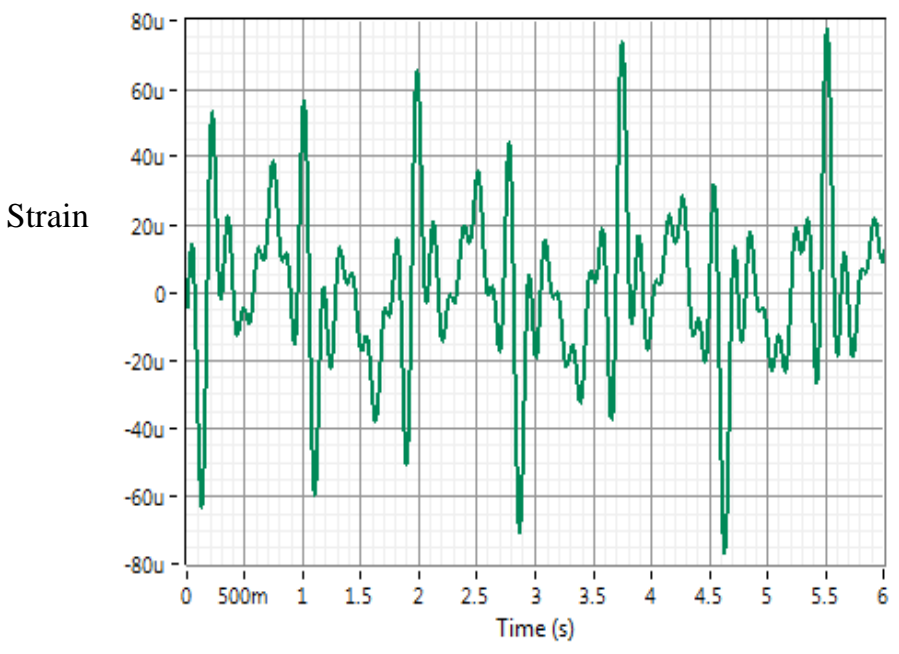

Fig (12) Strain verses time for ten spring and $0.75 \mathrm{~Hz}$

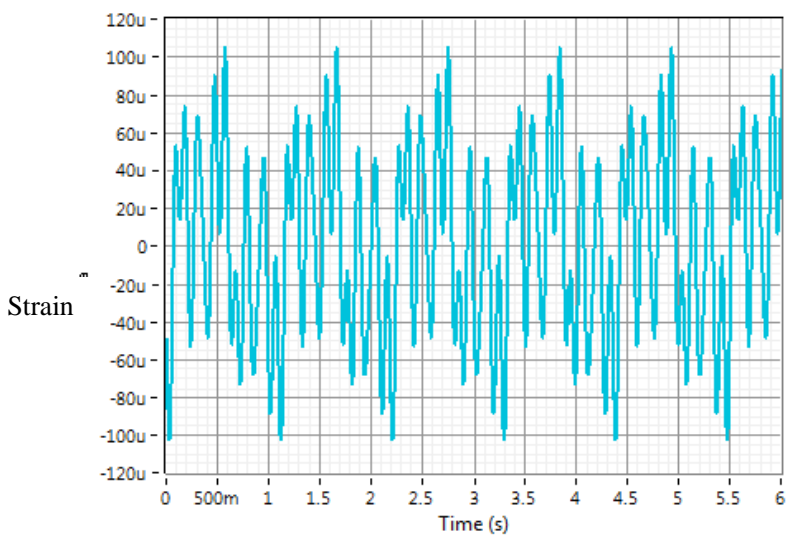

Fig (13) Strain verses time for ten spring and $1 \mathrm{~Hz}$

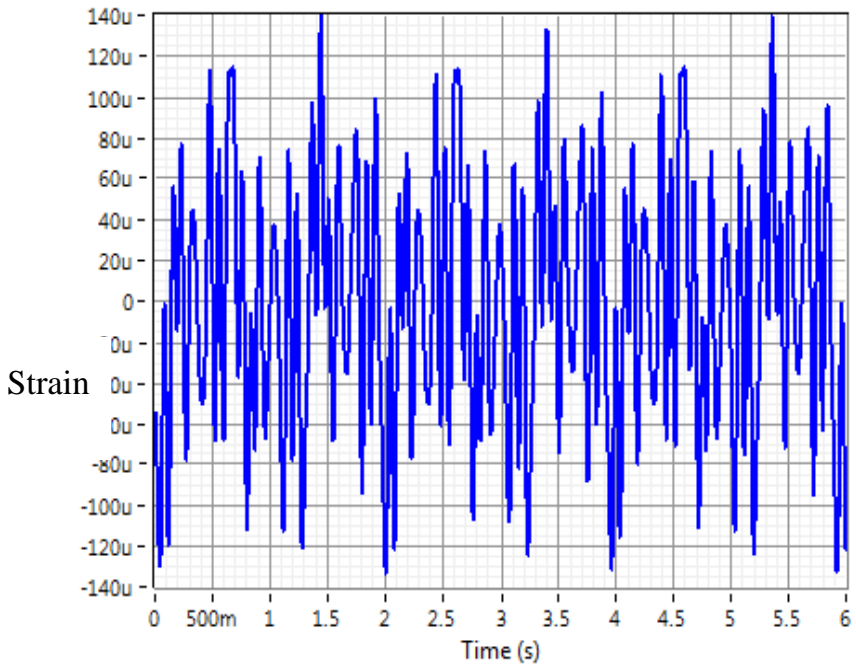

Fig (14) Strain verses time for ten spring and $1.25 \mathrm{~Hz}$ 5.2Strain of amidships point in rolling movement (MR)

The variation of dynamical vibration strain with the time at frequency of wave $(0.75 \mathrm{~Hz})$ and four springs $(4 \mathrm{~s})$ is shown in figure (12). From this figure it can be illustrated that the dynamical strain response variation between the hogging and sagging from rest to time (6sec).the value of strain reach to $(125 \mu)$ and $(-125 \mu)$.

Figure (13) observes the variation of dynamical vibration strain with the time at frequency of wave $(1 \mathrm{~Hz})$ and four springs (4s). It can be illustrated that the dynamical strain response variation between the hogging and sagging from rest to time $(6 \mathrm{sec})$.the value of strain reach to $(200 \mu)$ and ($200 \mu)$.

Figure (14) shows the variation of dynamical vibration strain with the time at frequency of wave $(1.25 \mathrm{~Hz})$ and four spring (4s).It can be seen that the oscillation and dynamical strain amplitude recorded by hogging and sagging during the process ranging between $(300 \mu)$ and $(-300 \mu)$ from rest to time $(6 \mathrm{sec})$.

Figure (15) presents the variation of dynamical vibration strain with the time at frequency of wave $(0.75 \mathrm{~Hz})$ and eight springs (8s). It can be presented that the process in this case from the beginning until reaching $(6 \mathrm{sec})$ the dynamical strain oscillation between hogging and sagging. The maximum value of dynamical strain reach to $(130 \mu)$ and ($130 \mu$ ) tension and compression respectively. 
Figure (16) observes the variation of dynamical vibration strain with the time at external frequency $(1 \mathrm{~Hz})$ and eight spring $(8 \mathrm{~s})$.It can be shown that the oscillation of the dynamical vibration strain amplitude recorded by hogging and sagging during the process ranging between $(200 \mu)$ and $(-200 \mu)$ from rest to time $(6 \mathrm{sec})$.

Figure (17) illustrates the variation of dynamical vibratic strain with the time at frequency of sea wave $(1.25 \mathrm{~Hz})$ an eight springs $(8 \mathrm{~s})$. It can be illustrated oscillation of th dynamical vibration strain amplitude recorded by hoggin and sagging during the process ranging between $(250 \mu$ and $(-250 \mu)$ from rest to time $(6 \mathrm{sec})$.

Figure (18) presents the variation of dynamical vibration strain with the time at external frequency $(0.75 \mathrm{~Hz})$ and ten spring (10s).It can be shown that the process in this case from the beginning until reaching $(6 \mathrm{sec})$ the dynamical strain oscillation between hogging and sagging. The maximum value of dynamical strain reach to $(120 \mu)$ and ($120 \mu$ ) hogging and sagging respectively.

Figure (19) illustrates the variation of dynamical vibration strain with the time at frequency of wave $(1 \mathrm{~Hz})$ and ten springs (10s). It can be illustrated oscillation of the dynamical vibration strain amplitude recorded by hogging and sagging during the process ranging between $(180 \mu)$ and $(-180 \mu)$ from rest to time $(6 \mathrm{sec})$.

Figure (20)observes the variation of dynamical vibre strain with the time at frequency of wave $(1.25 \mathrm{~Hz})$ anc $\mathbf{~} \mathrm{n}$ spring (10s).It can be shown that the oscillation of the dynamical vibration strain amplitude recorded by hogging and sagging during the process ranging between $(200 \mu)$ and $(-200 \mu)$ from rest to time $(6 \mathrm{sec})$.

Strain

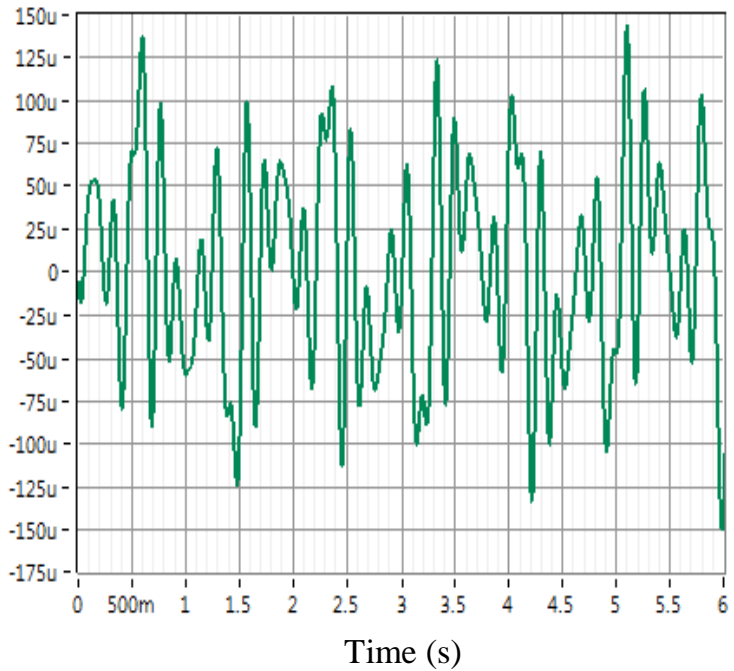

Fig (15) Strain verses time for four spring and $(0.75 \mathrm{~Hz})$

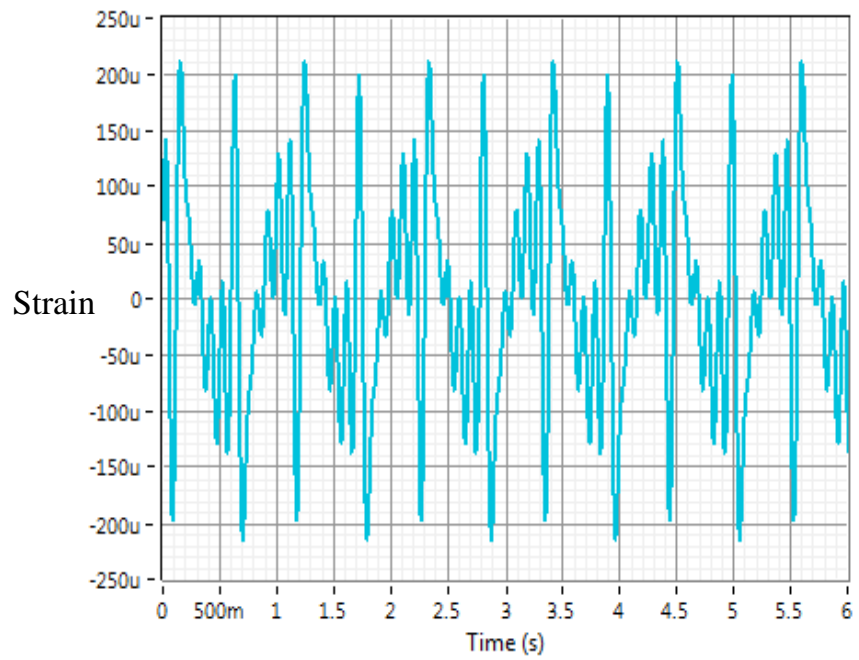

Fig (16) Strain verses time for four spring and1Hz

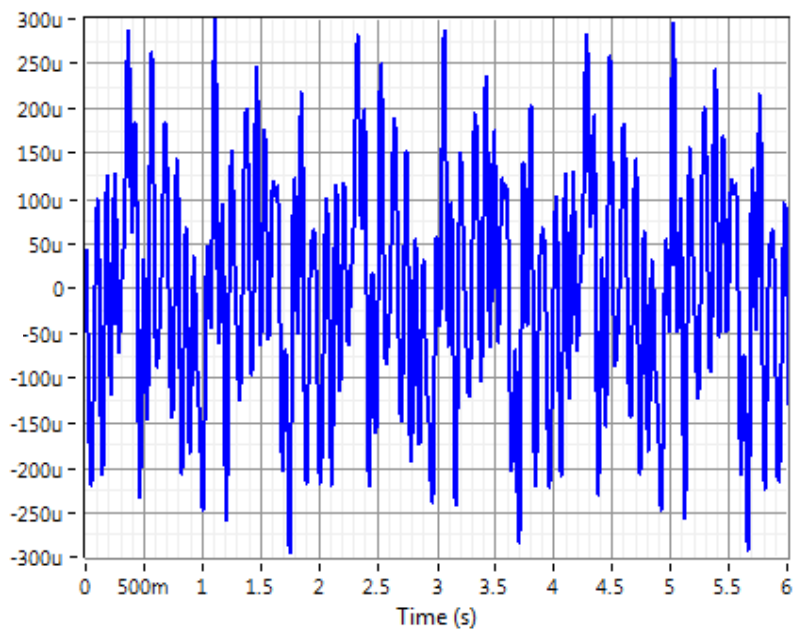

Fig (17) Strain verses time for four spring and $(1.25 \mathrm{~Hz})$

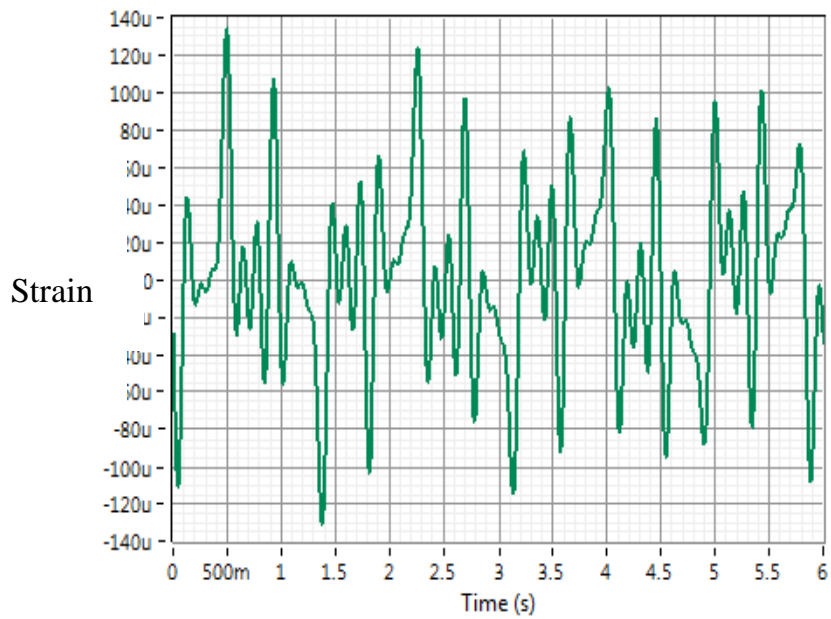

Fig (18) Strain verses time for eight spring and $0.75 \mathrm{~Hz}$ 
Strain

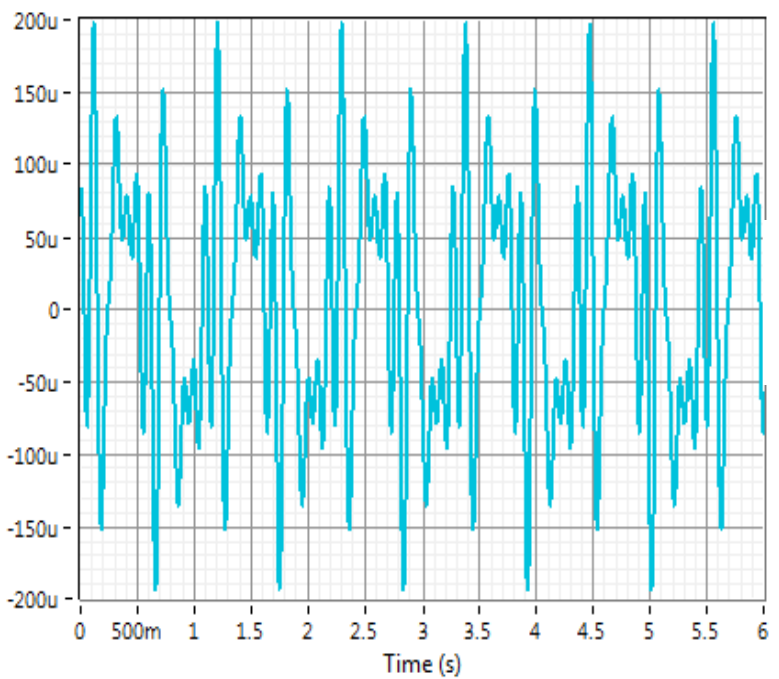

Fig (19) Strain verses time for eight spring and $1 \mathrm{~Hz}$

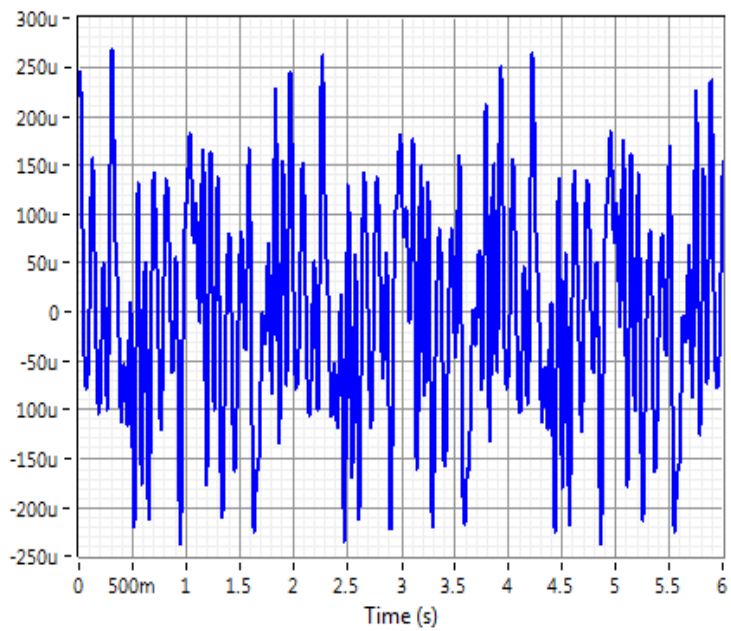

Fig (20) Strain verses time for eight spring and $1.25 \mathrm{~Hz}$

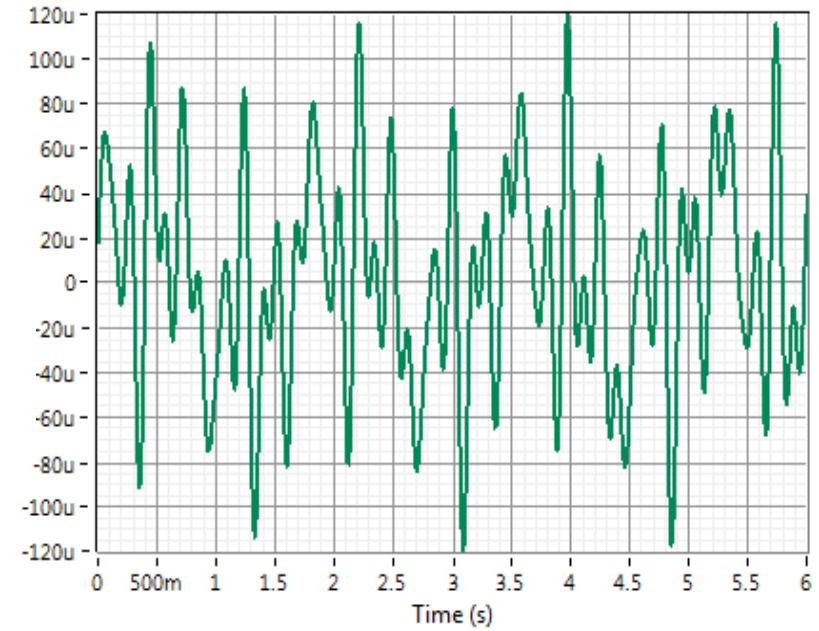

Fig (21) Strain verses time for ten spring and $0.75 \mathrm{~Hz}$

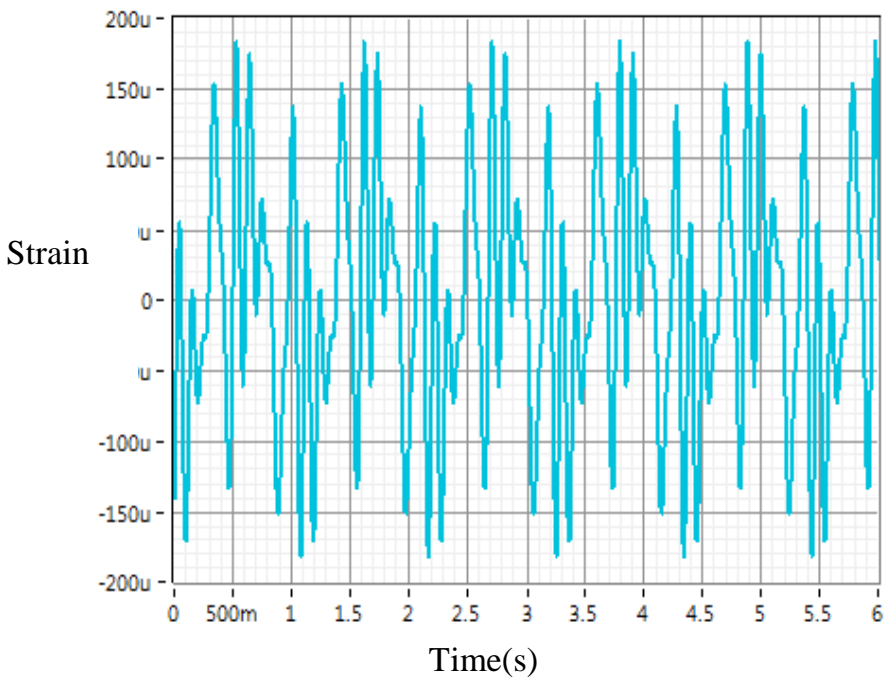

Fig (22) Strain verses time for ten spring and $1 \mathrm{~Hz}$

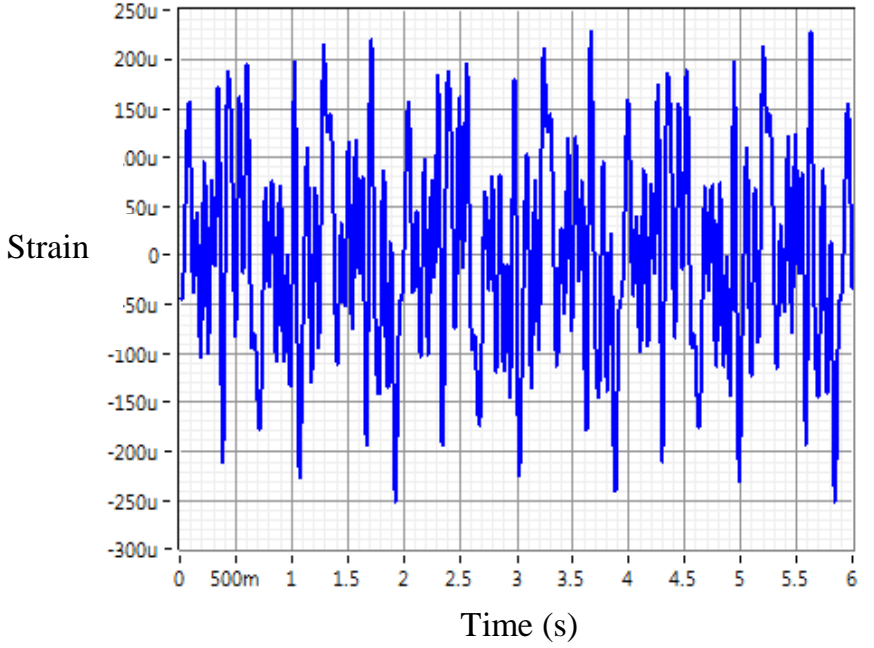

Fig (23) Strain verses time for ten spring and $1.25 \mathrm{~Hz}$

Figures $(24,25)$ illustrated the relationship between frequency and strain in cases $(4 \mathrm{~s}, 8 \mathrm{~s}$, and $10 \mathrm{~s})$. Increasing the frequency leads to increases the value of strains at all cases. The strain is higher in case four spring leading to damge in the middele of ship and breaking.

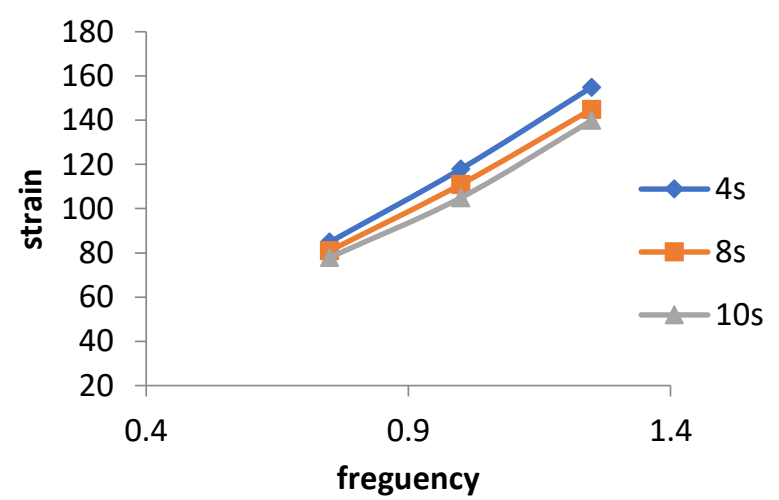

Fig (24)Variation between strain V.S frequencies at (MP). 


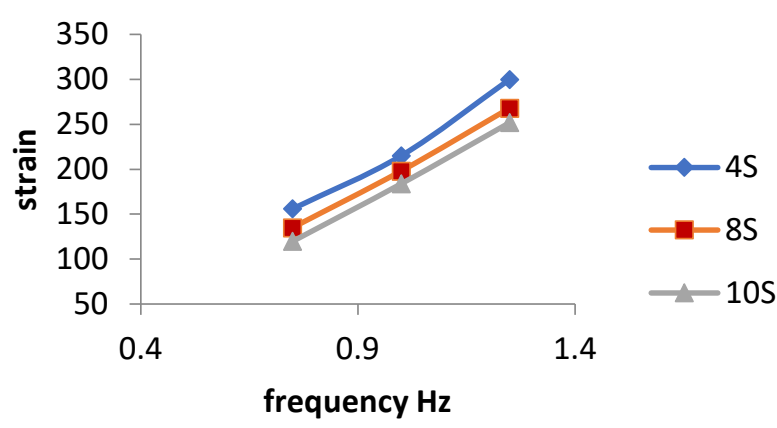

Fig (25) Variation between strain V.S frequencies at (MR). The comparison between rolling and pitching for ship hull movements lead to the rolling movement more effect from pitching in strain with increasing of frequency. As shown in figure (26).

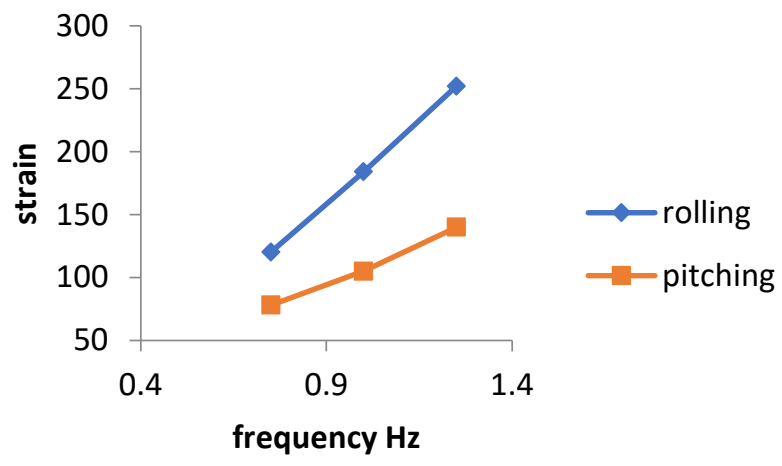

Fig (26)comparison between rolling and pitching

\section{Conclusions}

The main objective of this paper to calculate the strains of the ship hull model. The model was made of aluminum material and suitable dimensions and simulated sea water was carried out with elastic foundation under the ship using a number of springs connected to the ship and the other side to an iron base and was used several times to measure deformation. The results showed that:

1. When the frequency increases, the strains are increases because of vibration increasing.

2. When the number of springs increases, the strains are decreases as a result of little damping of the springs.

3. The strain in the rolling movement is greater than the strain in the pitching movement produce from that the stiffness of structure in longitudinal direction (pitching) is greater than in transverse direction (rolling), in addition to used keel structure in longitudinal direction.

\section{References}

[1] Dong Hengjian, 2009," Research on the influence of ship deformation on shafting system ", Journal of Ship Engineering. 3(2), 8-11.

[2] Shi, L., Xue, D., \& Song, X., 2010,"Research on shafting alignment considering ship hull
[3] Huang, Q., Zhang, C., Jin, Y., Yuan, C., \& Yan, X. (2015). Vibration analysis of marine propulsion shafting by the coupled finite element method. Journal ofVibroengineering, 17(7), 3392-3403.

[4] Xu, B., Duan, T., \& Wang, Y. (2017). An inertial measurement method of ship deformation based on IMM filtering. Optik, 140, 601-609..

[5] Akpan, U. O., Koko, T. S., Ayyub, B., \& Dunbar, T. E. (2002)," Risk assessment of aging ship hull structures in the presence of corrosion and fatigue ". Marine structures, 15(3), 211-231.

[6] Drummen, I., Storhaug, G., \& Moan, T. (2008). Experimental and numerical investigation of fatigue damage due to wave-induced vibrations in a containership in head seas. Journal of marine science and technology, 13(4), 428-445.

[7] Papanikolaou, A. (2010). Holistic ship design optimization. Computer-Aided Design, 42(11), 1028-1044. [8] Ibrahim, R. A., \& Grace, I. M. (2010). Modeling of ship roll dynamics and its coupling with heave and pitch. Mathematical Problems in Engineering, 2010.

[9] Wang, Y., Chen, J., \&Gai, S. (2016, April). The Study on the effect of wave load on the ship hull deformation. In 2016 International Conference on Civil, Structure and Environmental Engineering. Atlantis Press.

[10]Li, Y., Wang, Y., \& Cui, L. 2016," The Study on the Influence of Wave Load on The Vibration of Shaft system". In 2016 International Conference on Civil, Structure and Environmental Engineering. Atlantis Press

[11] Barrass, B., \&Derrett, C. D. (2011). Ship stability for masters and mates. Elsevier.

[12] Misra, S. C. (2015). Design principles of ships and marine structures. CRC Press.

[13]_04https://es.scribd.com/document/339297267/BulkCarrier-Handymax-General-Arrangement-Santa-Vessels 